\section{Dossier}

The Fischer-Tropsch Process Le procédé Fischer-Tropsch

\title{
Reactor Modeling of a Slurry Bubble Column for Fischer-Tropsch Synthesis
}

\author{
J.M. Schweitzer and J.C. Viguié \\ Institut français du pétrole, IFP, Process Design and Modeling Division, PO Box 3, 69390 Vernaison - France \\ e-mail: j-marc.schweitzer@ifp.fr - j-christophe.viguie@ifp.fr
}

\begin{abstract}
Résumé - Modélisation d'un réacteur à colonne à bulles pour la synthèse Fischer-Tropsch Un modèle complet de réacteur à colonne à bulles pour la synthèse Fischer-Tropsch a été développé, prenant en compte les caractéristiques hydrodynamiques des trois phases (gaz de synthèse, mélange liquide de paraffines linéaires et catalyseur solide) ainsi que la thermodynamique et les transferts de chaleur et de masse. Ce modèle est aussi capable de prendre en compte le recyclage du gaz après des étapes de condensation. Les résultats de simulation sont comparés aux données industrielles venant d'une unité de démonstration.
\end{abstract}

\begin{abstract}
Reactor Modeling of a Slurry Bubble Column for Fischer-Tropsch Synthesis A complete reactor model was developed for a slurry bubble column for Fischer-Tropsch synthesis in taking into account the hydrodynamic features of the three phases (syngas, liquid mixture of linear paraffins and solid catalyst) and including thermodynamics and heat and mass transfers. This model was also able to take into account the gas recycle after condensation steps. Simulation results were compared with industrial data coming from a demonstration unit.
\end{abstract}




\section{NOMENCLATURE}

A total molar flow-rate (mol/s)

$a_{i}, b_{i}$ coefficients for $K_{i}$ correlations

$a_{w} \quad$ volumetric exchange area of the exchanger $\left(\mathrm{m}^{2} / \mathrm{m}^{3}\right)$

$b \quad$ inhibition constant $\left(\mathrm{bar}^{-0.5}\right)$

$C_{\mathrm{CO}} \mathrm{CO}$ concentration in the liquid $\left(\mathrm{mol} / \mathrm{m}^{3}\right)$

$C_{\mathrm{CO}}^{*} \mathrm{CO}$ concentration in the liquid at equilibrium $\left(\mathrm{mol} / \mathrm{m}^{3}\right)$

$C_{\mathrm{H}_{2}}$ hydrogen concentration in the liquid ( $\left.\mathrm{mol} / \mathrm{m}^{3}\right)$

$C_{\mathrm{H}_{2}}^{*}$ hydrogen concentration in the liquid at equilibrium $\left(\mathrm{mol} / \mathrm{m}^{3}\right)$

$C_{p} \quad$ slurry heat capacity $(\mathrm{J} / \mathrm{kg} / \mathrm{K})$

$C_{p}^{g} \quad$ gas heat capacity $(\mathrm{J} / \mathrm{mol} / \mathrm{K})$

$D_{a x} \quad$ axial dispersion coefficient of the liquid $\left(\mathrm{m}^{2} / \mathrm{s}\right)$

E activation energy $(\mathrm{J} / \mathrm{mol})$

$F_{\text {CO }}^{g}$ molar flowrate of $\mathrm{CO}$ in the gas $(\mathrm{mol} / \mathrm{s})$

$F_{\mathrm{H}_{2}}^{g} \quad$ molar flowrate of hydrogen in the gas (mol/s)

$F_{\mathrm{H}_{2} \mathrm{O}}^{g}$ molar flowrate of water in the gas $(\mathrm{mol} / \mathrm{s})$

$F_{\mathrm{CO}}^{g o}$ initial CO flowrate in the gas $(\mathrm{mol} / \mathrm{s})$

$F_{\mathrm{H}_{2}}^{g o}$ initial $\mathrm{H}_{2}$ flowrate in the gas $(\mathrm{mol} / \mathrm{s})$

$F_{i, p}^{g} \quad$ molar flowrate of paraffin $i$ in the gas $(\mathrm{mol} / \mathrm{s})$

$F_{i, o l}^{g} \quad$ molar flowrate of olefin $i$ in the gas $(\mathrm{mol} / \mathrm{s})$

$F_{\mathrm{CO}}^{\text {tot }}$ total $\mathrm{CO}$ flow-rate $(\mathrm{mol} / \mathrm{s})$

$F_{\mathrm{CO}}^{\text {toto }}$ inlet total CO flowrate $(\mathrm{mol} / \mathrm{s})$

$F_{\mathrm{H}_{2}}^{\text {tot }}$ total hydrogen flowrate $(\mathrm{m} / \mathrm{s})$

$F_{\mathrm{H}_{2} \mathrm{O}}^{\text {tot }}$ total water flowrate $(\mathrm{m} / \mathrm{s})$

$F_{\text {inert }}$ total inert flowrate $(\mathrm{mol} / \mathrm{s})$

$F_{i, p}^{\text {tot }} \quad$ total flowrate of paraffin $i$ in gas and liquid phases (mol/s)

$F_{i, o l}^{\text {tot }} \quad$ total flowrate of olefin $i$ in gas and liquid-phases (mol/s)

$F_{o b j}$ objective function

$F_{s y n}^{o} \quad$ initial syngas flow-rate $(\mathrm{mol} / \mathrm{s})$

$g$ gravity constant $\left(\mathrm{m} / \mathrm{s}^{-2}\right)$

$H$ reactor height (m)

$\mathrm{H}_{\mathrm{CO}}$ Henry coefficient of $\mathrm{CO}$ (bar.m $\mathrm{m}^{3} / \mathrm{mol}$ )

$\mathrm{H}_{\mathrm{H}_{2}}$ Henry coefficient of hydrogen (bar. $\mathrm{m}^{3} / \mathrm{mol}$ )

$k \quad$ kinetic constant

$k_{o} \quad$ kinetic frequency factor

$K_{i} \quad$ partition coefficient of compound $i$

$K_{L}$.a mass transfer coefficient $\left(\mathrm{s}^{-1}\right)$

$L \quad$ liquid molar flow-rate (mol/s)

$M_{m}^{l} \quad$ molecular weight of the wax $\left(\mathrm{mol} / \mathrm{m}^{3}\right)$

$n_{p}^{\max }$ maximum paraffin carbon number

$n_{o l}^{\max }$ maximum olefin carbon number

$n_{p}^{\text {mean }}$ mean paraffin carbon number of the equivalent paraffin/olefin

$n_{o l}^{\text {mean }}$ mean olefin carbon number of the equivalent paraffin/olefin

$n_{\mathrm{H}_{2}}^{\text {mean }}$ mean hydrogen molecule of the equivalent paraffin

$P_{\mathrm{CO}} \quad \mathrm{CO}$ partial pressure (bar)
$\mathrm{Pe} \quad$ liquid Peclet number

$P e_{T}$ thermal Peclet number

$P_{H_{2}} \quad$ hydrogen partial pressure (bar)

$P_{\mathrm{H}_{2} \mathrm{O}}^{v a p} \quad$ vapor pressure of the water (bar)

$P_{t} \quad$ total pressure (bar)

$Q_{g}^{N C P T}$ syngas flow-rate $\left(\mathrm{Nm}^{3} / \mathrm{s}\right)$

$R \quad$ constant of the ideal gas $8.314(\mathrm{~J} / \mathrm{mol} / \mathrm{K})$

$\mathrm{r}_{\mathrm{CO}}$ kinetic rate of $\mathrm{CO}$ conversion ( $\mathrm{mol} / \mathrm{kg}$ cat $/ \mathrm{s}$ )

$S_{o l} \quad$ olefin weight selectivity

$S_{r} \quad$ reactor section $\left(\mathrm{m}^{2}\right)$

$T \quad$ reactor temperature $(\mathrm{K})$

$T_{\text {cool }}$ cooling temperature (K)

$T_{i n j} \quad$ gas inlet temperature (K)

$T_{\text {outlet }}$ reactor outlet temperature (K)

$T_{r} \quad$ kinetic reference temperature (K)

$T_{x}^{\text {inert }}$ inert ratio

$U$ heat transfer coefficient $\left(\mathrm{W} / \mathrm{m}^{2} / \mathrm{K}\right)$

$V \quad$ vapor molar flow-rate $(\mathrm{mol} / \mathrm{s})$

$v_{s g} \quad$ superficial gas velocity $(\mathrm{m} / \mathrm{s})$

$v_{s l} \quad$ slurry superficial velocity $(\mathrm{m} / \mathrm{s})$

$x_{\mathrm{CH}_{4}}$ methane selectivity

$x_{i}^{o l} \quad$ molar fraction of olefin $i$

$x_{i}^{p} \quad$ molar fraction of paraffin $i$

$x_{i} \quad$ molar fraction of compound $i$ in the liquid

$y_{i} \quad$ molar fraction of compound $i$ in the gas

$z \quad$ vertical axis

$z^{*} \quad$ normalized axis to the total reactor height

$z_{i} \quad$ total molar fraction of compound $i$

\section{Greek letters}

$\alpha_{1} \quad$ Schultz-Flory parameter for paraffins

$\alpha_{2} \quad$ Schultz-Flory parameter for olefins

$\beta \quad$ stoechiometric coefficient of the equivalent paraffin

$\Delta H_{r}$ reaction heat $(\mathrm{J} / \mathrm{mol})$

$\zeta \quad \mathrm{H}_{2} / \mathrm{CO}$ ratio

$\varepsilon_{g} \quad$ gas holdup

$\varepsilon_{s} \quad$ volumetric solid concentration in the slurry

$\Phi \quad$ Weisz criteria

$\lambda_{a x}$ axial thermal conductivity $(\mathrm{W} / \mathrm{m} / \mathrm{K})$

$v \quad$ vapor molar fraction

$\mu \quad$ stoechiometric coefficient of hydrogen

$\rho_{l} \quad$ wax density $\left(\mathrm{kg} / \mathrm{m}^{3}\right)$

$\rho_{s} \quad$ dry solid particle density $\left(\mathrm{kg} / \mathrm{m}^{3}\right)$

$\rho_{s l} \quad$ slurry density $\mathrm{k}\left(\mathrm{g} / \mathrm{m}^{3}\right)$

$\tau \quad$ slurry residence time (s)

$\chi \quad$ CO conversion 


\section{INTRODUCTION}

Fischer-Tropsch synthesis is a very important issue for the petroleum companies because it is a way to produce clean fuels from natural gas (Fischer et al., 1921). The slurry bubble column seems to be the most appropriate reactor for this reaction (Mills et al., 1996). In fact, three phases are involved in this reaction where the gas phase (syngas) is the reactant, the liquid phase (mixture of linear paraffins) is the reaction products and the solid phase is the catalyst on which the reaction occurs. This reaction is highly exothermic and fine particles of catalyst are necessary to avoid internal diffusional limitations.

A complete reactor model was developed taking into account the hydrodynamic features of the three phases, the thermodynamics, the heat and mass transfers. This model was also able to take into account the gas recycle after condensation steps. Then simulation results were compared with industrial data coming from the demonstration unit in Italy.

\section{FISCHER-TROPSCH REACTION}

The reaction converts the syngas into a mixture of linear paraffins (Fischer et al., 1921).

$$
\underbrace{\mathrm{CO}+2 \mathrm{H}_{2}}_{\text {syngas }} \rightarrow \underbrace{-\left(\mathrm{CH}_{2}\right)-}_{n \text { paraffin }}+\mathrm{H}_{2} \mathrm{O} \quad \Delta H_{r}=-167093 \mathrm{~J} / \mathrm{mol}
$$

The syngas is a mixture of carbon monoxide and hydrogen. This gas could be obtained from the partial oxidation (1) + steam reforming (2) of the natural gas (methane), or by autothermal reforming (combined reactions $(1)+(2)$ in a single reactor).

$$
\begin{aligned}
& \underbrace{\mathrm{CH}_{4}}_{\text {natural gas }}+\frac{1}{2} \mathrm{O}_{2} \rightarrow \underbrace{\mathrm{CO}+2 \mathrm{H}_{2}}_{\text {syngas }} \\
& \underbrace{\mathrm{CH}_{4}}_{\text {natural gas }}+2 \mathrm{H}_{2} \mathrm{O} \rightarrow \underbrace{\mathrm{CO}+4 \mathrm{H}_{2}}_{\text {syngas }}
\end{aligned}
$$

The Fischer-Tropsch reaction follows a polymeric kinetic process, which can be decomposed, into 3 steps (simplified scheme):

- initiation step: formation of the first $\mathrm{CH}_{2}$ group;

- propagation step: chain length growing by addition of other $\mathrm{CH}_{2}$ groups;

- termination step: hydrogenation of the edge $\mathrm{CH}_{2}$ groups of a given chain.

The stoechiometry of the reaction is a little bit complicated due to the termination step. The stoechiometric coefficient of the hydrogen is greater than 2 in order to satisfy this third step. The determination of this coefficient is described in the following paragraph. The stoechiometry is also depending on the other product selectivities (olefins, which are in fact the

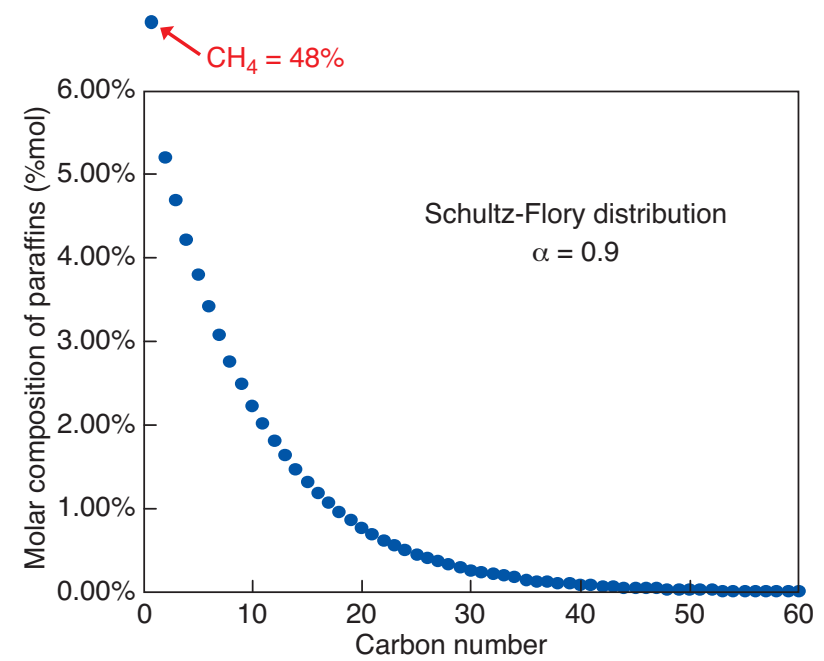

Figure 1

Schultz-Flory distribution.

primary products of the reaction by $\beta-\mathrm{H}$ abstraction from $\mathrm{CH}_{2}$ growing -chain) by-products (alcohols, other oxygenates) and methane selectivities. In the next step, only paraffins, olefins and methane are considered.

\subsection{Stoechiometry}

The stoechiometry of the reaction depends on the catalyst selectivity. According to the experimental data from the literature, the product selectivity follows a Schulz-Flory distribution (Schulz et al., 1988). Figure 1 shows a typical Schulz-Flory distribution for paraffins obtained on Cobalt catalyst for a given set of operating conditions.

Olefins are produced with a given weight selectivity $S_{o l}$. Olefin molar selectivity follows a Schulz-Flory distribution as for paraffins. This Schulz-Flory distribution is based on a chain-length-growing coefficient called $\alpha$. Then we can distinguished two distributions one for paraffins with a chain length growing coefficient $\alpha_{1}$ and one for the olefins with a corresponding coefficient $\alpha_{2}$. Then, molar fraction of paraffins and olefins can be defined as follow:

$\alpha=$ Schultz - Flory parameter $=$ molar ratio $\frac{C_{n+1}}{C_{n}}$

for paraffins

$x_{i}^{p}=K_{1} \cdot\left(1-\alpha_{1}\right) \cdot \alpha_{1}^{i-1} \quad 2 \leq i \leq n_{p}^{\max }$

for olefins

$$
x_{i}^{o l}=K_{2} \cdot\left(1-\alpha_{2}\right) \cdot \alpha_{2}^{i-1} \quad 2 \leq i \leq n_{o l}^{\max }
$$

This distribution is valid only for paraffins having at least two carbon atoms. In fact, for methane, Schulz-Flory 
distribution is not followed. Then, it was shown in the literature, that its selectivity is fixed by the catalyst and the operating conditions and is independent on the distribution. With this Schulz-Flory distribution it is possible to calculate the stoechiometric coefficients for the hydrogen. Two equations are necessary to find the values of coefficient $K_{1}$ and $K_{2}$.

$$
\begin{gathered}
\sum_{i=1}^{n_{p}^{\max }} x_{i}^{p}+\sum_{i=1}^{n_{o l}^{\max }} x_{i}^{o l}=1 \Rightarrow \\
x_{1}^{p}+K_{1} \cdot\left(1-\alpha_{1}\right) \cdot \sum_{i=2}^{n_{p}^{\max }} \alpha_{1}^{i-1}+K_{2} \cdot\left(1-\alpha_{2}\right) \cdot \sum_{i=2}^{n_{o l}^{\max }} \alpha_{2}^{i-1}=1 \\
\text { and } S_{o l}=\frac{\sum_{i=2}^{n_{o l}^{\max }} x_{i, w}^{o l}}{\sum_{i=1}^{\max } x_{i, w}^{p}+\sum_{i=1}^{n_{o l}^{\max }} x_{i, w}^{o l}}= \\
\sum_{i=2}^{n_{o l}^{\max }} x_{i}^{o l} \cdot(12 . i+2 . i) \\
\sum_{i=1}^{n_{p}^{\max }} x_{i}^{p} \cdot(12 . i+2 . i+2)+\sum_{i=1}^{n_{o l}^{\max }} x_{i}^{o l} \cdot(12 . i+2 . i)
\end{gathered} \Rightarrow \begin{gathered}
\text { See } \\
\text { Equation }
\end{gathered}
$$

With these distributions, it is interesting to have the average stoechiometric coefficient for hydrogen and equivalent paraffin/olefin. For this, consider the following reaction:

$$
\underbrace{\mathrm{CO}+\mu \mathrm{H}_{2}}_{\text {syngas }} \rightarrow \underbrace{\beta P_{\text {paraffin/olefin }}^{e q}}_{\text {equivalent }}+\mathrm{H}_{2} \mathrm{O}
$$

The average number of carbon atoms in the equivalent paraffin/olefin is given by:

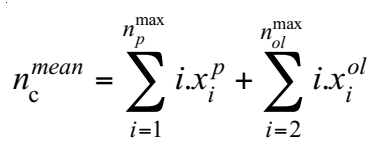

The average number of hydrogen molecule contained in one molecule of equivalent paraffin/olefin is given by:

$$
n_{\mathrm{H}_{2}}^{\text {mean }}=\sum_{i=1}^{n_{p}^{\max }}(i+1) \cdot x_{i}^{p}+\sum_{i=2}^{n_{o l}^{\max }} i \cdot x_{i}^{o l}
$$

One mole of carbon monoxide produces $\beta$ moles of equivalent paraffin/olefin. The molar carbon balance leads to:

$$
\begin{aligned}
& \beta . n_{c}^{\text {mean }}=1 \\
& \text { Then } \beta=\frac{1}{\sum_{i=1}^{n_{p}^{\max } i . x_{i}^{p}+\sum_{i=2}^{n_{o l}^{\max }} i . x_{i}^{o l}}}
\end{aligned}
$$

The molar hydrogen balance leads to:

$$
\begin{gathered}
\mu=\underbrace{1}_{\text {hydrogen in water }}+\underbrace{\beta . n_{\mathrm{H}_{2}}^{\text {mean }}}_{\text {hydrogen in equivalent paraffin/olefin }} \\
\Rightarrow \mu=1+\frac{\sum_{i=1}^{n_{p}^{\max }(i+1) \cdot x_{i}^{p}}+\sum_{i=2}^{n_{o l}^{\max } i \cdot x_{i}^{o l}}}{\sum_{i=1}^{n_{p}^{\max } i . x_{i}^{p}+\sum_{i=2}^{n_{o l}^{\max }} i \cdot x_{i}^{o l}}}=2+\frac{\sum_{i=1}^{n_{p}^{\max }} x_{i}^{p}}{\sum_{i=1}^{n_{p}^{\max } i \cdot x_{i}^{p}+\sum_{i=2}^{n_{o l}^{\max }} i \cdot x_{i}^{o l}}} \\
\Rightarrow \mu=2+\beta . \sum_{i=1}^{n_{p}^{\max } x_{i}^{p}}
\end{gathered}
$$

By knowing the $\alpha$ coefficients and the methane selectivity, it is possible to determine the molar fraction of each paraffin and the stoechiometric coefficients of the reaction. Table 1 shows the influence of the $\alpha$ values and olefin selectivity on the stoechiometry. An increase of the $\alpha$ coefficient leads to a selectivity oriented towards the high chain lengths.

TABLE 1

Effect of selectivity on stoechiometry

\begin{tabular}{c|c|c|c}
\hline$S_{o l}$ & $\alpha_{1}$ & $\alpha_{2}$ & $\mu_{\mathrm{H}_{2}}$ \\
\hline 0.15 & 0.9 & 0.72 & 2.1688 \\
\hline 0.05 & 0.9 & 0.72 & 2.1673 \\
\hline 0.15 & 0.92 & 0.8 & 2.1389 \\
\hline
\end{tabular}

\subsection{Kinetics}

Some kinetic studies were performed on a Cobalt based catalyst in autoclave reactors. There are many kinetic models in the literature (Yates and Satterfield, 1991; Sarup et al., 1989). It appears that the kinetic rate follows the SarupWojciechowski kinetic model.

$$
S_{o l}=\frac{K_{2} \cdot\left(1-\alpha_{2}\right) \cdot \sum_{i=2}^{n_{o l}^{\max }} \alpha_{2}^{i-1} \cdot(12 . i+2 . i)}{16 \cdot x_{1}^{p}+K_{1} \cdot\left(1-\alpha_{1}\right) \cdot \sum_{i=2}^{n_{p}^{\max }} \alpha_{1}^{i-1} \cdot(12 . i+2 . i+2)+K_{2} \cdot\left(1-\alpha_{2}\right) \cdot \sum_{i=2}^{n_{o l}^{\max }} \alpha_{2}^{i-1} \cdot(12 . i+2 . i)}
$$


$r_{\mathrm{CO}}=\frac{k \cdot\left(P_{\mathrm{CO}}\right)^{0.5} \cdot\left(P_{\mathrm{H}_{2}}\right)^{0.5}}{\left(1+b \cdot\left(P_{\mathrm{CO}}\right)^{0.5}\right)^{2}} \mathrm{~mol} / \mathrm{s} / \mathrm{kg} \mathrm{cat}$

$k=k_{r} \cdot \mathrm{e}^{\left(-E / R \cdot\left(1 / T-1 / T_{r}\right)\right)} \mathrm{mol} / \mathrm{s} / \mathrm{kg}$ cat $/ \mathrm{bar}$

$b$ in $\operatorname{bar}^{-0.5}$

$T_{r}=$ reference temperature $E=$ activation energy

In this kinetic expression, an inhibition term is taken into account in order to represent the decrease of the number of active sites due to a high $\mathrm{CO}$ partial pressure. The activity is taken into account through a reference temperature. In fact, the kinetic coefficient can be written as follow:

where $k_{o}=k_{r} \cdot e^{\frac{E}{R T_{r}}}$ is the kinetic frequency factor, which quantifies the intrinsic activity of the catalyst. This activity can be adjusted by means of a kinetic reference temperature $T_{r}$. The higher reference temperature is, the lower activity is.

\section{SLURRY BUBBLE COLUMN REACTORS}

Slurry bubble column reactors are simple vertical cylindrical vessels with intense contact between the three phases: the gas reactant injected at the bottom of the column, the liquid product and the solid catalyst. The "liquid + catalyst" suspension is called slurry. The gas phase is dispersed into the liquid phase using specific gas distributor at the bottom of the column. A simplified representation of a slurry bubble column is shown in Figure 2.

Most of dispersing energy in the bubble column is introduced with the gas phase at the bottom of the column. Therefore, movement of fluids occurs by natural dynamics of the phases: catalyst particles are in suspension in the mixed liquid phase. It is well-known from literature that at sufficient gas throughput, in the churn-turbulent regime, the liquid is drawn upwards in the core region and when the bubbles disengage at the top, the liquid returns down near the wall region (see Fig. 3). These results have been often observed but generally in small column $(D<0.2 \mathrm{~m})$, without internals and with air-water systems. The centerline liquid velocity $V_{L}(0)$ measured along the axis of the column is the maximum upward time averaged liquid velocity (Miyauchi et al., 1970; Hills, 1974).

Due to specific hydrodynamics, slurry bubble columns therefore possess many attractive features:

- a high liquid mixing which provides homogeneous catalyst concentration and temperature: thus an efficient heat transfer and temperature control is obatined;

- the use of small mean catalyst particles size diameters (about $50 \mu \mathrm{m}$ ) which avoid intra-granular diffusionnal limitations;

- easy catalyst addition and withdrawal.

These reactors present also some drawbacks:

- large reactors are required because of the low catalyst concentration compared to fixed bed;

- reliable scale-up and design criteria are still missing: for instance a too high liquid recirculation could generate catalyst attrition and internals abrasion;

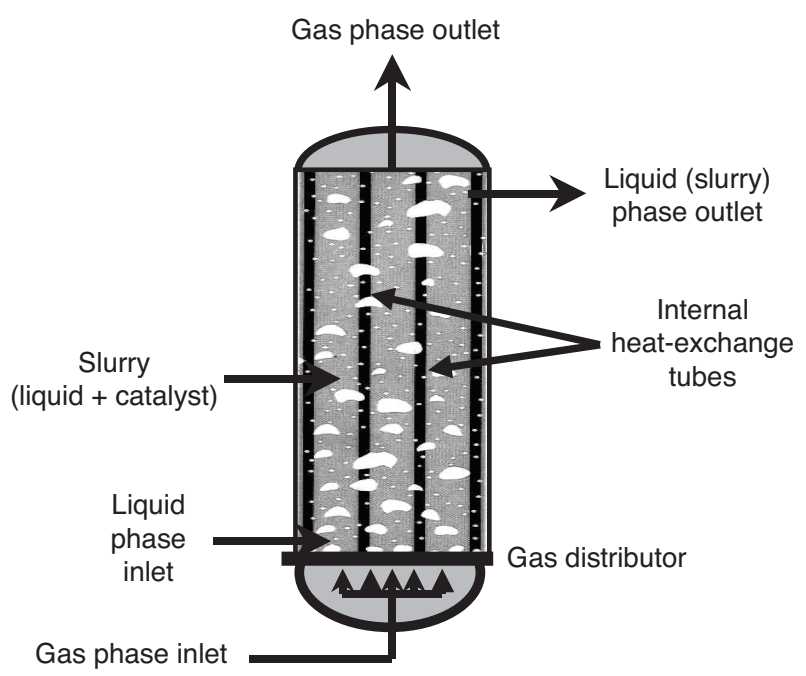

Figure 2

Slurry bubble column reactors.

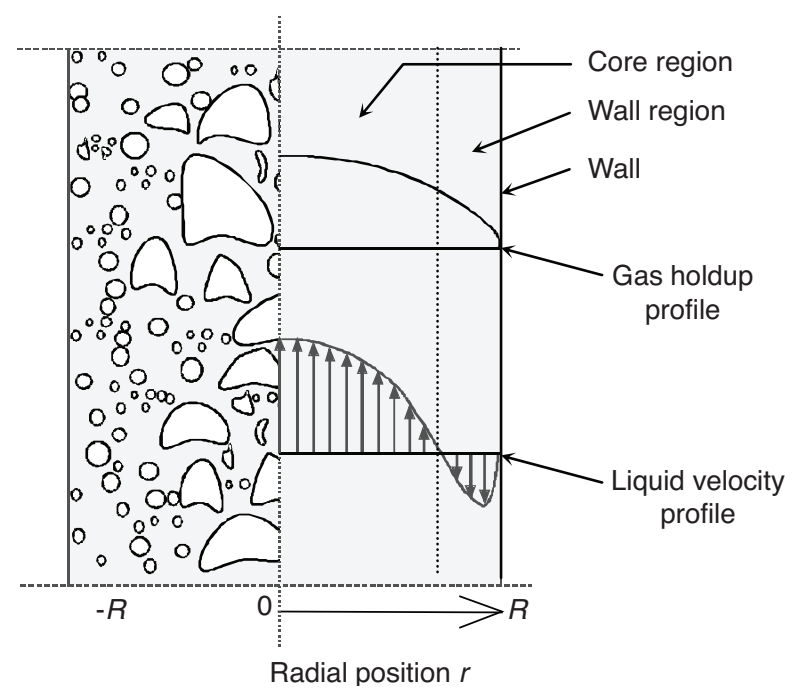

Figure 3

Liquid velocity profiles in churn turbulent regime. 
- the continuous separation of fine solid catalyst particles from the liquid products is difficult;

- slurry handling requires careful design to avoid plugging.

\subsection{Importance of Hydrodynamics}

The reactor performance and volumetric productivity and selectivity are affected significantly by the fluid dynamics which are not yet well understood due to the complexity of the flow field in slurry bubble reactors.

Also, the success of the Fischer-Tropsch process (Krishna, 2000) largely depends on the ability to achieve deep syngas conversions, approaching $90 \%$ or higher. But reliable design of the reactor to achieve such high conversion levels requires reasonable accurate information on the following hydrodynamic, mass and heat transfer parameters: gas holdup, interphase mass transfer between the gas bubbles and the slurry, axial dispersion of the slurry and heat transfer coefficient to cooling tubes.

Slurry bubble columns are operated in either semi-batch mode (zero liquid throughput) or with liquid superficial velocity lower than the gas superficial velocity by at least an order of magnitude. As a result, the gas flow controls the fluid dynamics of each phase. It affects liquid mixing and interface mass transfer, which subsequently controls conversion and selectivity.

\subsubsection{Bubble Characteristics and Gas Holdup}

In the literature, attention to gas holdup prevails because gas holdup affects mixing and mass transfer, and therefore, the performance of the system. Gas holdup is influenced by many parameters, including particle concentration, electrolyte concentration, liquid viscosity and surface tension. The residence time of a small bubble is longer than that of a large bubble, because the rise velocity of a bubble increases with the square root of its size (Kluytmans, 2001). Hence, a smaller average bubble size leads to an increase in gas holdup. Also a swarm of bubbles rises much faster than single, isolated bubbles (Krishna et al., 1999). The trend observed for a single bubble is the same than for a swarm of bubbles: a swarm of smaller average bubble size leads to an increase in gas holdup. Bubble diameters $d_{b}$ and gas holdup are then intimately linked.

All published papers which deal with surface tension effect on gas holdup are consistent: as the surface tension is a measure for the stability of the gas-liquid interface, a smaller surface tension leads to a less stable gas-liquid interface and thus to a smaller average bubble size and an increase of gas holdup. Adding even a small amount of surface-active material to water such alcohol or electrolyte reduces surface tension and leads to a strong increase of gas holdup. The higher gas holdup was attributed to a decrease in or suppression of coalescing tendencies (Keitel and Onken, 1982; Fan, 1989).
According to a lot of authors (Krishna et al., 2000; Kelkar and Shah, 1984; Bach and Pilhofer, 1978) an increase in liquid viscosity will decrease gas holdup. The increase in viscosity leads to larger stable bubbles and thus higher bubble rise velocities and lower gas holdup. Urseanu (2000) distinguished the contribution of the large bubbles and the dense phase (little bubbles dispersed in the liquid) to the total gas holdup: the difference in the large bubble holdup with liquid properties is very small. However, the dense phase holdup decreases dramatically with increasing viscosity of the liquid phase.

The fine catalyst particles are intimately mixed with the liquid and the slurry phase can be considered pseudo-homogeneous (Krishna, 2000). In a slurry bubble column using fine particles (< $100 \mu \mathrm{m})$, (Fan, 1989; Gandhi et al., 1999), the gas holdup decreases with an increase in solids concentration. The most plausible explanation for this seemingly varied behavior is that increasing solids concentration increases the "pseudo-viscosity" of the suspension which in turn promotes the bubble coalescence, resulting in an increase in bubble size and a decrease in gas holdup. According to Krishna (2000), there is a deep decrease of the gas holdup when the solid concentration increases from 0 to $15 \%$; then, the gas holdup decreases more slightly when the solid concentration varies from 20 to $30 \%$. The concentration of solid particles also affects the transition to the heterogeneous flow regime, which occurs at a lower superficial gas velocity when solid concentration increases.

According to Krishna et al. (1991), it does not matter whether the increased gas density is a result of operation at higher pressure or due to the use of a gas with higher molar mass. The major effect of increased gas density is to stabilize the regime of homogeneous bubble flow and, consequently, to delay the transition to the churn-turbulent flow regime. It was observed (Reilly et al., 1986; Idogawa et al., 1987; Wilkinson and Van Dierendonck, 1990) that the gas holdup increases with gas density due to a reduction of bubble size. This was attributed to a decrease in bubble stability and a decrease in the coalescing rate with an increase in the gas density. Both these factors favor into an increase in the gas holdup.

The fraction of large bubbles decreases with increasing pressure, and narrower bubble size distributions are observed at higher pressures (Jiang et al., 1995). The pressure mainly affects the fraction of large bubbles. Moreover, it has also been observed (Clark, 1990; Letzel et al., 1999; Kemoun et al., 2001) that with an increase in pressure, bubble stability increases and the transition to churn-turbulent regime characterized by the change of the radial gas holdup profile from relatively flat to almost parabolic, is delayed to higher superficial gas velocities.

According to Joshi (1998) and Shah et al. (1982), in the heterogeneous regime, the average fractional gas holdup is independent of the column diameter when. 
Berg (1993) has performed gas holdup measurement in three column diameters $(0.290 ; 0.441$ and $0.450 \mathrm{~m})$ with different internals configurations (open free area ranging from 70 to $100 \%$, number of tubes up to 91 with a diameter of $25 \mathrm{~mm}$ with various arrangements). He reported that internals do not affect the global gas holdup for superficial gas velocity up to $0.60 \mathrm{~m} / \mathrm{s}$.

\subsubsection{Liquid Flow Pattern Correlations}

Most of the existing correlations for the axial dispersion coefficient are developed and based on data with air-water system at atmospheric conditions.

An analogy between eddy diffusivity $E$ and axial dispersion coefficient $D_{a x}$ can be done (Baird and Rice, 1975). In the case of eddy diffusivity, it can been shown by dimensional analysis that:

$$
E=K l^{4 / 3} P_{m}^{1 / 3}
$$

It is assumed here that the largest eddies, which are mainly responsible for eddy diffusion, are related to a primary length parameter $l$ and to the specific energy dissipation rate $P_{m}$. The constant $K$ is dimensionless and should have an universal value, provided the length parameter $l$ is suitably defined for different system geometries. If we consider a unit-sided cube of a gas-liquid dispersion in a bubble column, the vertical hydrostatic pressure gradient is $-\rho_{L} g(1-\varepsilon)$ and the specific energy dissipation rate in the continuous phase is $P_{m}=U_{g} \cdot g$. It is assumed that the energy dissipation in the gas bubbles is negligible. The liquid phase velocity is assumed to be low enough not to have a significant effect on $P_{m}$. At very low gas rates, the bubbles rise individually and are separated by stagnant regions. The turbulence model does not apply to this case. At high gas rates, the bubble wakes interact and the liquid phase is more uniformly turbulent. The bubbles themselves can be carried out about in the eddies and the primary length parameter $l$ is obviously greater than the bubbles diameter. In the simple case of a column without any baffles, packing or other internals, Baird and Rice (1975) assume that the primary length parameter $l$ is the column diameter $D$. Hence, from the above equations: $E=K D^{4 / 3}\left(U_{g} g\right)^{1 / 3}$.

In general (Fan, 1989), the liquid axial dispersion coefficient in a bubble column is proportional to the 0.3-0.5 power of superficial gas velocity, proportional to $1.25-1.5$ power of column diameter, decreases slightly with an increase of liquid viscosity and is essentially unaffected by the liquid surface tension in the coalesced bubble regime.

So, the exponents of $D$ and $U_{g}$ for the eddy diffusivities and for the axial dispersion coefficient are very close, suggesting a correspondence between the model for eddy diffusivity $E$ and the data for axial dispersion coefficient $D_{a x}$. It may be concluded that the simple relationship $D_{a x} \approx 0.35 D^{4 / 3}\left(P_{m}\right)^{1 / 3}$ can be used for "order of magnitude" estimates of the axial dispersion coefficient in unbaffled bubble columns under turbulent conditions. The correlation should be used with particular caution in the case of small diameter columns where slug flow is a possibility, and in short columns $(H / D<5)$. It should be noted that the turbulence in a bubble column is not necessarily isotropic. Reith $e t$ al. (1968) found that the axial dispersion coefficient considerably exceeded the radial dispersion coefficient.

\subsection{Mass Transfer}

The performance of a multiphase chemical reactor is linked with the exchange between phases. This is particularly true for slurries reactors, where reactants are in the gas phase and where the reaction occurs in the slurry phase.

Due to the small size of catalyst particles in slurry reactors, intraparticle diffusion is not a limiting factor (Krishna, 2000). To confirm this point, a comparison between the chemical production flux and the diffusion flux in pores of the reactants is necessary. This is done by means of the Weisz criteria (Froment et al., 1979).

$\Phi=\frac{\text { Chemical production flux }}{\text { Diffusion flux }}=\frac{\left(r \cdot \rho_{s}\right)_{o b s} \cdot\left(\frac{d_{p}}{6}\right)^{2}}{D_{\mathrm{CO}} \cdot[\mathrm{CO}]}$

$\Phi>>1$ Performances governed by the diffusion in pores

$\Phi<1$ Performances governed by the chemical reaction

Table 2 shows the values of the Weisz criteria obtained for a given catalyst (the present one) with two different sizes: one corresponding to the size for fixed bed reactor, an the other for the slurry bubble column reactor.

TABLE 2

Catalyst internal transport

\begin{tabular}{c|c|c|c|c}
\hline $\begin{array}{c}\text { Reactor } \\
\text { type }\end{array}$ & $\begin{array}{c}\text { Pressure } \\
\text { bar }\end{array}$ & $\begin{array}{c}\text { Temperature } \\
{ }^{\circ} \mathrm{C}\end{array}$ & $\begin{array}{c}\text { Particle } \\
\text { diameter }(\mathrm{mm})\end{array}$ & $\begin{array}{c}\text { Weisz } \\
\text { criteria }\end{array}$ \\
\hline SBC & 20 & 225 & 0.06 & 0.026 \\
\hline Fixed bed & 20 & 225 & 1 & 7.330 \\
\hline
\end{tabular}

It is clearly shown that for the catalyst size used in the slurry bubble column, the Weisz criteria is far below 1 ( 2 order of magnitude). This confirms that there are no internal diffusionnal limitations of the reactants.

With catalysts of relatively low activity present in low concentration in bubble columns operated in the homogeneous regime, gas-liquid mass transfer is unlikely to be a limiting factor either in view of the large surface area of the small bubbles or their long residence time in the liquid. However, for reactors of increased productivity, because of the use of more active catalysts at high concentrations and operation in the heterogeneous regime, gas-liquid mass transfer can become a factor that needs serious consideration. The gas-liquid mass transfer rate is determined to a large extent 
by the bubble diameter and gas hold-up. Quality and structure of the interfacial area itself also affect the rate of mass transfer which is dependent upon it. Hence (Deckwer, 1992), a low mass transfer rate is found when bubbles are small and have a relatively rigid surface, whereas bubbles with a larger diameter and a mobile, oscillating surface encourage a high level of turbulence which results in high rates of mass transfer. Bubble rise velocity and hence gas phase residence time are also a function of bubble size. The latter frequently have an extremely wide distribution pattern which may incorporate several peaks. Non-uniform bubble size and the subsequent difference in bubble rise velocity generate a wider gas phase residence time distribution. According to Nigam and Schumpe (1996), interfacial area $a$ is one of the most important parameters for gas-liquid reactor design. It is the most influential factor in determining reactor output, especially in the region in which absorption is accompanied by fast chemical reaction. In general, the gas-liquid interfacial area is a function of the unit's geometric size, operating parameters and the physical and chemical properties of specific material systems. In the case of absorption accompanied by slow or instantaneous reaction, the mass transfer rate is determined by the volumetric mass transfer coefficient $k_{L} \cdot a$ which is a function of the specific area $a$. The latter represents the amount of interfacial area with respect to the dispersion volume. When mass transfer occurs from gas bubbles to the surrounding liquid in a bubble or slurry bubble column, the gasside resistance can often be neglected in determining the overall gas-liquid mass transfer resistance due to the low solubility of gas in the liquid. Thus the gas-liquid mass transfer rate per unit volume of aerated liquid (or slurry) can often be defined in terms of the liquid-side volumetric mass transfer coefficient $k_{L} \cdot a$. As a general rule, absorption rate (local or integral) can be described by :

$$
\Phi=k_{L} \cdot a \cdot\left(\frac{P}{H_{e}}-C_{0}\right)
$$

All the effects shown above on bubble size affect directly the interfacial area $a$ and thus the mass transfer coefficient $k_{L} \cdot a$. A lot of parallels between gas holdup and $k_{L} \cdot a$ can therefore be made. The most accepted correlations for $k_{L} \cdot a$ in the literature are those of Akita and Yoshida (1973) and Calderbank and Moo-Young (1961), but these correlations were obtained in bubble columns operating in the homogeneous regime and are able to describe only mass transfer for small bubbles, which are considered as rigid spheres. Now, large bubbles continuously coalesce and break-up, while rising along the column, at a very high frequency, between 2 and $16 \mathrm{~Hz}$ (de Swart et al., 1996). This is very important for interface mass transfer, because the really large sized bubbles have only a momentary existence. Hence, gas-liquid interface renewal is very frequent and mass transfer characteristics of such large bubbles are better than those predicted by conventional theories.

\subsection{Industrial Applications}

Slurry bubble column reactors or three-phase fluidized bed reactors possess many attractive features which make them a suitable choice for carrying out highly exothermic reaction, for example in the Fischer-Tropsch conversion of syngas to liquid hydrocarbons.

The anticipated dimensions and operating conditions of an industrial unit are given in Table 3 .

TABLE 3

Anticipated Fischer-Tropsch large scale plant dimension and operating conditions

\begin{tabular}{c|c}
\hline Diameter $D(\mathrm{~m})$ & $5-10$ \\
\hline Height $H(\mathrm{~m})$ & $20-40$ \\
\hline Pressure $p($ bar $)$ & $20-30$ \\
\hline Temperature $T\left({ }^{\circ} \mathrm{C}\right)$ & $200-240$ \\
\hline Superficial gas velocity $U g(\mathrm{~m} / \mathrm{s})$ & $0.1-0.3$ \\
\hline Volume fraction of catalyst $\varepsilon_{s}(-)$ & $0.15-0.3$ \\
\hline
\end{tabular}

\section{REACTOR MODELING}

The reactor model is shown in Figure 4. The general assumptions are the following:

- the flow pattern of the gas phase is considered to be plug flow, which is an acceptable assumption according to the Peclet number measured by radioactive tracer test in cold mock-up (Peclet number for small bubbles $=6$ and Peclet number for large bubbles $=41$ );

- the flow pattern of the slurry phase is considered to follow the dispersed-plug flow model, characterized by a slurry Peclet number measured by radioactive tracer test in cold mock-up;

- the reactants in the gas phase transfer to the liquid phase. This mass transfer is characterized by a gas/liquid mass transfer coefficient $k_{L} \cdot a$. The same mass transfer coefficient is used for all the reactants;

- the dissolved reactants react in contact with the catalyst to produce water, normal paraffins, olefins and heat. The reaction rate follows the Sarup and Wojciechowski kinetic law;

- the heat transport follows also the dispersed-plug-flow model by using the same Peclet number than the one used for the slurry phase;

- the temperatures in the solid, liquid and gas phases are the same;

- the gas and the liquid composition profiles are calculated by a two-phase flash calculation based on the SoaveRedlich-Kwong equation of state;

- the heat removal is taken into account by a heat transfer term representing the heat exchanger; 


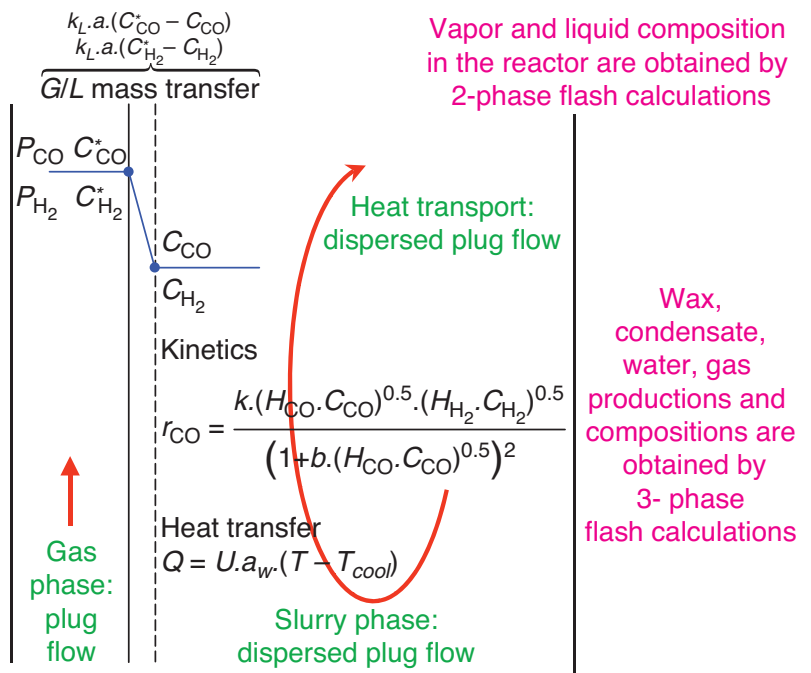

Figure 4

Reactor model.

- a three-phase flash calculation is performed at the reactor outlet in order to estimate the liquid water, gas, condensate and wax production and corresponding compositions going out of the unit.

\subsection{Transient Material Balance of Reactant in the Gas Phase}

\subsubsection{Transient Material Balance for Carbon Monoxide $\mathrm{CO}$ in the Gas Phase:}

$$
\begin{aligned}
& \underbrace{\frac{\partial F_{\mathrm{CO}}^{g}}{\partial z}}_{\text {convective term }}+\underbrace{k_{L} \cdot a \cdot S_{r} \cdot\left(1-\varepsilon_{g}\right) \cdot\left(\frac{P_{\mathrm{CO}}}{H_{\mathrm{CO}}}-C_{\mathrm{CO}}\right)}_{\text {gas/liquid mass transfer term }} \\
& =\frac{\partial\left(\frac{F_{\mathrm{CO}}^{g}}{u_{g}}\right)}{\partial t}
\end{aligned}
$$

where $\varepsilon_{g}$ is the volume of gas per reactor volume, $C_{\mathrm{CO}}$ the concentration of $\mathrm{CO}$ in the liquid phase $\mathrm{mol} / \mathrm{m}^{3}$ of liquid phase, $a$ the interfacial area of gas in $\mathrm{m}^{2}$ of gas $/ \mathrm{m}^{3}$ of slurry.

\subsubsection{Transient Material Balance for Hydrogen $\mathrm{H}_{2}$ in the Gas Phase:}

$$
\frac{\partial F_{\mathrm{H}_{2}}^{g}}{\partial z}+k_{L} \cdot a \cdot S_{r} \cdot\left(1-\varepsilon_{g}\right) \cdot\left(\frac{P_{\mathrm{H}_{2}}}{H_{\mathrm{H}_{2}}}-C_{\mathrm{H}_{2}}\right)=\frac{\partial\left(\frac{F_{\mathrm{H}_{2}}^{g}}{u_{g}}\right)}{\partial t}
$$

\subsection{Transient Material Balance of Reactant in the Liquid Phase}

\subsubsection{Transient Material Balance for Carbon Monoxide $\mathrm{CO}$ in the Liquid Phase:}

$$
\begin{aligned}
& \underbrace{D_{a x} \cdot \frac{\partial^{2} C_{\mathrm{CO}}}{\partial z^{2}}}_{\text {dispersion term }}-\underbrace{\frac{v_{s l}}{\left(1-\varepsilon_{g}\right)} \cdot \frac{\partial C_{\mathrm{CO}}}{\partial z}}_{\text {convective term }}-\underbrace{\frac{\varepsilon_{s}}{1-\varepsilon_{s}} \cdot \rho_{s} \cdot r_{\mathrm{CO}}}_{\text {production term }}+ \\
& \underbrace{\frac{k_{L} \cdot a}{1-\varepsilon_{s}} \cdot\left(\frac{P_{\mathrm{CO}}}{H_{\mathrm{CO}}}-C_{\mathrm{CO}}\right)}_{\text {gas/liquid mass transfer term }}=\frac{\partial C_{\mathrm{CO}}}{\partial t}
\end{aligned}
$$

In a non-dimensional form:

$$
\begin{aligned}
& \frac{1}{P e} \cdot \frac{\partial^{2} C_{\mathrm{CO}}}{\partial z^{* 2}}-\frac{1}{\left(1-\varepsilon_{g}\right)} \cdot \frac{\partial C_{\mathrm{CO}}}{\partial z^{*}}-\frac{\varepsilon_{s}}{1-\varepsilon_{s}} \cdot \rho_{s} \cdot \tau \cdot r_{\mathrm{CO}}+ \\
& \frac{k_{L} \cdot a}{1-\varepsilon_{s}} \cdot \tau \cdot\left(\frac{P_{\mathrm{CO}}}{H_{\mathrm{CO}}}-C_{\mathrm{CO}}\right)=\tau \cdot \frac{\partial C_{\mathrm{CO}}}{\partial t}
\end{aligned}
$$

with:

$$
P e=\frac{v_{s l} . H}{D_{a x}}, \quad \tau=\frac{H}{v_{s l}}, \quad z^{*}=\frac{z}{H}
$$

\subsubsection{Transient Material Balance for Hydrogen $\mathrm{H}_{2}$} in the Liquid Phase:

$$
\begin{aligned}
& D_{a x} \cdot \frac{\partial^{2} C_{\mathrm{H}_{2}}}{\partial z^{2}}-\frac{v_{s l}}{\left(1-\varepsilon_{g}\right)} \cdot \frac{\partial C_{\mathrm{H}_{2}}}{\partial z}-\mu \cdot \frac{\varepsilon_{s}}{1-\varepsilon_{s}} \cdot \rho_{s} \cdot r_{\mathrm{CO}}+ \\
& \frac{k_{L} \cdot a}{1-\varepsilon_{s}} \cdot\left(\frac{P_{\mathrm{H}_{2}}}{H_{\mathrm{H}_{2}}}-C_{\mathrm{H}_{2}}\right)=\frac{\partial C_{\mathrm{H}_{2}}}{\partial t}
\end{aligned}
$$

In a non-dimensional form:

$$
\begin{aligned}
& \frac{1}{P e} \cdot \frac{\partial^{2} C_{\mathrm{H}_{2}}}{\partial z^{* 2}}-\frac{1}{\left(1-\varepsilon_{g}\right)} \cdot \frac{\partial C_{\mathrm{H}_{2}}}{\partial z^{*}}-\mu_{\mathrm{H}_{2}} \cdot \frac{\varepsilon_{s}}{1-\varepsilon_{s}} \cdot \rho_{s} \cdot \tau \cdot r_{\mathrm{CO}}+ \\
& \frac{k_{L} \cdot a}{1-\varepsilon_{s}} \cdot \tau \cdot\left(\frac{P_{\mathrm{H}_{2}}}{H_{\mathrm{H}_{2}}}-C_{\mathrm{H}_{2}}\right)=\tau \cdot \frac{\partial C_{\mathrm{H}_{2}}}{\partial t}
\end{aligned}
$$

\subsection{Transient Heat Material Balance}

$$
\begin{aligned}
& \underbrace{\lambda_{a x} \cdot \frac{\partial^{2} T}{\partial z^{2}}}_{\text {dispersion term }}-\underbrace{\rho_{s l} \cdot C_{p} \cdot \frac{v_{s l}}{\left(1-\varepsilon_{g}\right)} \cdot \frac{\partial T}{\partial z}}_{\text {convective term }}-\underbrace{\varepsilon_{s} \cdot \rho_{s} \cdot r_{\mathrm{CO}} \cdot \Delta H_{r}}_{\text {production term }}+ \\
& \underbrace{\frac{U \cdot a_{w}}{1-\varepsilon_{g}} \cdot\left(T-T_{\text {cool }}\right)}_{\text {transfer term }}=\rho_{s l} \cdot C_{p} \cdot \frac{\partial T}{\partial t}
\end{aligned}
$$


In a non-dimensional form:

$$
\begin{aligned}
& \frac{1}{P e_{T}} \cdot \frac{\partial^{2} T}{\partial z^{* 2}}-\frac{1}{\left(1-\varepsilon_{g}\right)} \cdot \frac{\partial T}{\partial z^{*}}-\frac{\varepsilon_{s} \cdot \rho_{s} \cdot \tau \cdot r_{\mathrm{CO}} \cdot \Delta H_{r}}{\rho_{s l} \cdot C_{p}}+ \\
& \frac{\frac{U \cdot a_{w}}{1-\varepsilon_{g}} \cdot \tau \cdot\left(T-T_{c o o l}\right)}{\rho_{s l} \cdot C_{p}}=\tau \cdot \frac{\partial T}{\partial t}
\end{aligned}
$$

with

$$
P e_{T}=\frac{\rho_{s l} \cdot C_{p} \cdot v_{s l} \cdot H}{\lambda_{a x}}, \quad \tau=\frac{H}{v_{s l}}, \quad z^{*}=\frac{z}{H}
$$

The cooling temperature is constant along the reactor because the reaction heat is removed by water vaporization in the cooling tubes. During the water vaporization, the temperature does not change.

\subsection{Pressure Drop}

In slurry bubble columns the pressure drop due to the friction can be neglected compare to the static height. Then, the pressure drop becomes:

$$
\frac{\partial P_{t}}{\partial z}=-\left(1-\varepsilon_{g}\right) \cdot g \cdot \rho_{s l}
$$

where $\rho_{s l}$ is the slurry density, $\mathrm{kg} / \mathrm{m}^{3}$.

\subsection{Two Phase Flash Calculation}

For each elementary volume, the total composition of each compound $\left(z_{i}\right)$ is calculated. These compositions can be determined from the conversion and the total molar flowrates as follow:

$$
\text { conversion: } \quad \chi=\frac{F_{\mathrm{CO}}^{\text {tot } o}-F_{\mathrm{CO}}^{\text {tot }}}{F_{\mathrm{CO}}^{\text {tot } o}}
$$

total molar flowrate of CO: $F_{\mathrm{CO}}^{t o t}=F_{\mathrm{CO}}^{g}+v_{s l} \cdot S_{r} \cdot\left(1-\varepsilon_{s}\right) \cdot C_{\mathrm{CO}}$ total molar flowrate of $\mathrm{H}_{2}: F_{\mathrm{H}_{2}}^{t o t}=F_{\mathrm{H}_{2}}^{g}+v_{s l} \cdot S_{r} \cdot\left(1-\varepsilon_{s}\right) \cdot C_{\mathrm{H}_{2}}$ total molar flowrate of $\mathrm{H}_{2} \mathrm{O}: \quad F_{\mathrm{H}_{2} \mathrm{O}}^{\text {tot }}=F_{\mathrm{CO}}^{\text {tot } o} \cdot \mathcal{\chi}$ total molar flowrate of paraffin: $F_{i, p}^{t o t}=F_{\mathrm{CO}}^{t o t o} \cdot \chi \cdot \beta \cdot x_{i}^{p}$ total molar flowrate of olefin $i: \quad F_{i, o l}^{\text {tot }}=F_{\mathrm{CO}}^{\text {tot } o} \cdot \chi \cdot \beta \cdot x_{i}^{o l}$

This leads to:

total molar flowrate:

$$
\begin{aligned}
& F_{t o t}=F_{\mathrm{CO}}^{t o t}+F_{\mathrm{H}_{2}}^{t o t}+F_{\mathrm{H}_{2} \mathrm{O}}^{t o t}+F_{\text {inert }}+\sum_{i=1}^{n_{p}^{\max }} F_{i, p}^{t o t}+\sum_{i=2}^{n_{o l}^{\max }} F_{i, o l}^{t o t} \\
& \text { total molar fraction of CO: } \quad z_{\mathrm{CO}}=\frac{F_{\mathrm{CO}}^{t o t}}{F_{\text {tot }}}
\end{aligned}
$$

$$
\begin{aligned}
& \text { total molar fraction of } \mathrm{H}_{2}: \quad z_{\mathrm{H}_{2}}=\frac{F_{\mathrm{H}_{2}}^{\text {tot }}}{F_{\text {tot }}} \\
& \text { total molar fraction of } \mathrm{H}_{2} \mathrm{O}: \quad z_{\mathrm{H}_{2} \mathrm{O}}=\frac{F_{\mathrm{H}_{2} \mathrm{O}}^{\text {tot }}}{F_{\text {tot }}} \\
& \text { total molar fraction of inert: } \quad z_{\text {inert }}=\frac{F_{\text {inert }}}{F_{\text {tot }}}
\end{aligned}
$$

total molar fraction of paraffins:

$$
z_{p}=\frac{F_{i, p}^{t o t}}{F_{t o t}} \text { for } i \in\left[1, n_{p}^{\max }\right]
$$

total molar fraction of olefins:

$$
z_{o l}=\frac{F_{i, o l}^{t o t}}{F_{t o t}} \text { for } i \in\left[2, n_{o l}^{\max }\right]
$$

The resolution of the gas/liquid equilibrium needs the values of the partition coefficients relative to each compound. These coefficients were determined using the Soave-RedlichKwong equation of state for different compositions and operating conditions. It was shown that the composition does not affect strongly these coefficients. Then, correlations were developed as a function of the operating conditions using an Antoine expression. The general form of these correlations is:

$$
\begin{aligned}
& \log _{10}\left(P_{t} \cdot K_{i}\right)=\frac{a_{i}}{T}+b_{i} \\
& \text { with } K_{i}=\frac{y_{i}}{x_{i}}, P_{t} \text { in bar, } T \text { in } \mathrm{K}
\end{aligned}
$$

For each compound, coefficients $a_{i}$ and $b_{i}$ are determined. Then, it is possible to calculate the partition coefficients for a given pressure and temperature. Figure 5 shows, for three different temperatures, a good agreement between the correlations and the results coming from the equation of state.

Remark: The correlations were developed in order to simplify the flash calculations an also to decrease the CPU time needed for the convergence.

Now, by writing the molar balances, it is possible to determine the flowrates and the compositions of the gas and the liquid phases.

$$
\left\{\begin{array}{l}
A . z_{i}=L \cdot x_{i}+V \cdot y_{i} \\
K_{i}=\frac{y_{i}}{x_{i}} \\
A=L+V
\end{array}\right.
$$

$A$ is the total molar flowrate, $L$ is the liquid molar flowrate, $V$ is the vapor molar flowrate, $x_{i}$ is the liquid molar 

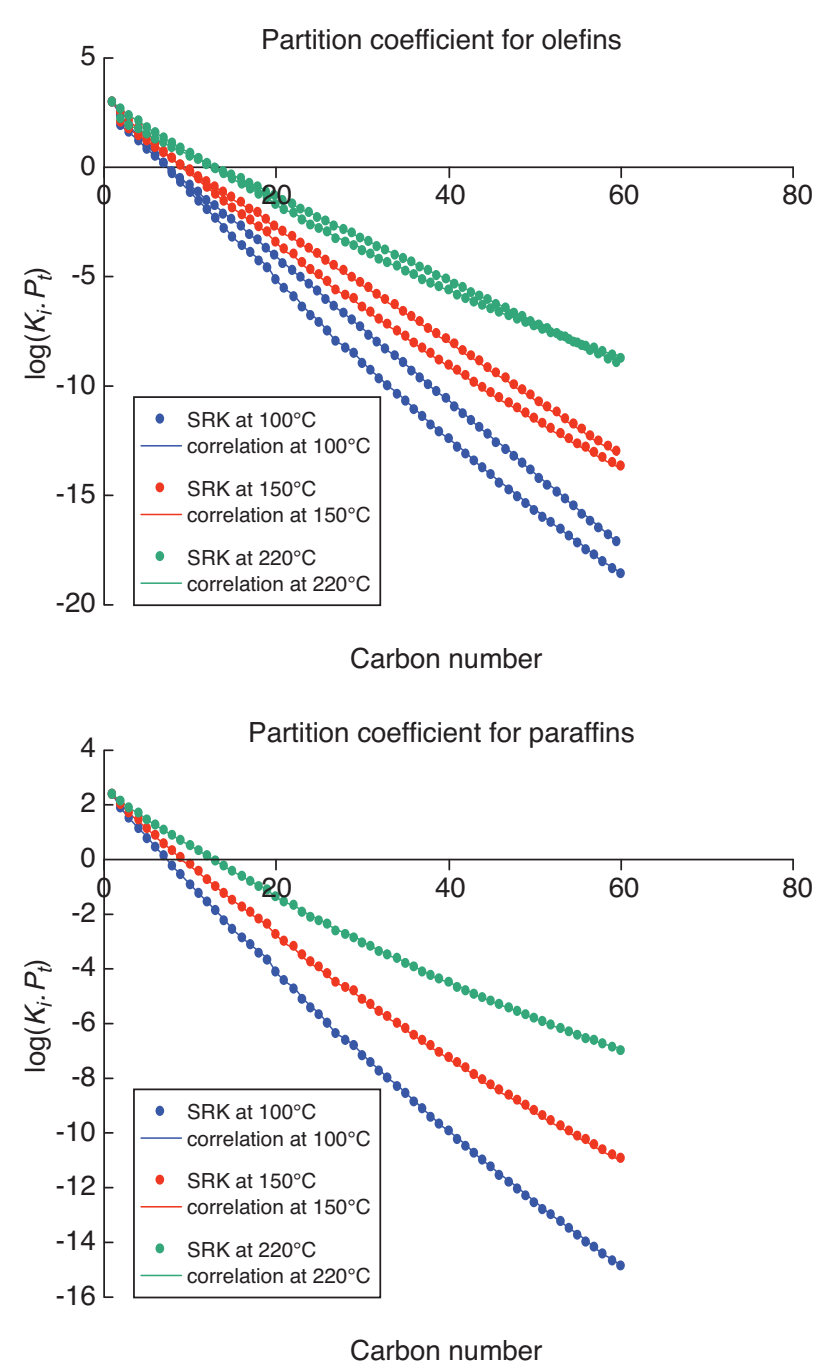

Figure 5

Comparison between SRK calculations and correlations for partition coefficient of paraffins and olefins.

fraction of the $i$ th compound and $y_{i}$ is the vapor molar flowrate of the $i$ th compound. This system of equations leads to:

$$
\begin{aligned}
& x_{i}=\frac{z_{i}}{1+v \cdot\left(K_{i}-1\right)} \\
& y_{i}=\frac{K_{i} \cdot z_{i}}{1+v \cdot\left(K_{i}-1\right)} \\
& \text { where } v=\frac{V}{A} \text { is the total vapor molar fraction }
\end{aligned}
$$

Then, an objective function can be defined:

$$
F_{o b j}=\sum_{i}\left(y_{i}-x_{i}\right)=0
$$

By adjusting $v$, the flash calculation is solved in order to have $F_{o b j}=0$.

Remark: the Henry coefficients for the $\mathrm{CO}$ and $\mathrm{H}_{2}$ are calculated from the corresponding partition coefficients as follow:

$$
H_{\mathrm{CO}}=\frac{K_{\mathrm{CO}} \cdot P_{t} \cdot M_{m}^{l}}{\rho_{l}} \quad H_{\mathrm{H}_{2}}=\frac{K_{\mathrm{H}_{2}} \cdot P_{t} \cdot M_{m}^{l}}{\rho_{l}}
$$

with:

$$
\begin{aligned}
& M_{m}^{l}=\text { molecular weight of the liquid phase }(\mathrm{kg} / \mathrm{mol}) \\
& \rho_{l}=\text { liquid specific gravity }\left(\mathrm{kg} / \mathrm{m}^{3}\right) \\
& H=\text { Henry coefficient }\left(\text { bar. } \mathrm{m}^{3} / \mathrm{mol}\right) \\
& P_{t}=\text { total pressure }(\text { bar }) \\
& K_{i}=\text { partition coefficient }
\end{aligned}
$$

\subsection{Three-Phase Flash Calculation}

At the reactor outlet, the gas phase is condensed at ambient temperature and process pressure. Then, three phases are present in this system: gas phase, light liquid hydrocarbons and liquid water. To estimate the flowrates and the compositions of the three phases, a three-phase flash calculation is needed. The vapor molar fraction of the water is determined from the vapor pressure of water at flash conditions. For this we use the correlation given in the literature.

$$
\begin{aligned}
& \log _{10}\left(P_{\mathrm{H}_{2} \mathrm{O}}^{\text {vap }}\right)=5.11564-\frac{1687.537}{T+230.17-273.15} \\
& \text { with } P_{\mathrm{H}_{2} \mathrm{O}}^{\text {vap }} \text { in bar, } T \text { in } \mathrm{K}
\end{aligned}
$$

$$
\text { Then, } y_{\mathrm{H}_{2} \mathrm{O}}=\frac{P_{\mathrm{H}_{2} \mathrm{O}}^{\text {vap }}}{P_{t}}
$$

When the vapor molar fraction of the water is determined, a two-phase flash calculation is then performed on the other compounds at the ambient temperature and at the pressure $P_{t}$ $-P_{\mathrm{H}_{2} \mathrm{O}}^{\mathrm{vap}}$ (see Sect. 3.5).

\subsection{Superficial Gas Velocity}

Due to the reaction, the gas is consumed. Then, the superficial gas velocity decreases along the reactor. It is necessary to calculate for each elementary volume the superficial gas velocity going through. For this, the ideal gas law is used:

$$
v_{s g}=\frac{\left(F_{\mathrm{CO}}^{g}+F_{\mathrm{H}_{2}}^{g}+F_{\mathrm{H}_{2} \mathrm{O}}^{g}+F_{\text {inert }}+\sum_{i=1}^{n_{p}^{\max }} F_{i, p}^{g}+\sum_{i=1}^{n_{o l}^{\max }} F_{i, o l}^{g}\right) \cdot R \cdot T}{P_{t} \cdot S_{r}}
$$


Remark: Inert compounds are considered to be completely in the gas phase.

\subsection{Gas Holdup}

The model for the gas holdup is based on the Krishna approach (Krishna et al., 1996; Krishna et al., 2000). The equations of the model are summarized below:

Gas holdup in the homogeneous regime:

$$
\varepsilon_{g}=\frac{v_{s g}}{V_{\text {small }}}
$$

Gas holdup at the transition:

$$
\varepsilon_{g}^{\text {trans }}=\frac{U_{\text {trans }}}{V_{\text {small }}}
$$

Gas holdup in the turbulent regime:

$$
\varepsilon_{g}=\varepsilon_{g}^{\text {trans }} \cdot\left(1-\varepsilon_{b}\right)+\varepsilon_{b}
$$

Gas holdup in the dilute phase:

$$
\begin{aligned}
& v_{s g}>U_{\text {trans }} \\
& \varepsilon_{b}=\alpha_{5} \cdot\left(\frac{1}{D}\right)^{\alpha_{6}} \cdot\left(\frac{1}{v_{s g}-U_{\text {trans }}}\right)^{\alpha_{7}} \cdot\left(v_{s g}-U_{\text {trans }}\right)^{0.8} \cdot \exp \left(-\alpha_{10} \cdot \varepsilon_{s}\right) \\
& \varepsilon_{s} \leq 0.1 \\
& v_{s g}>U_{\text {trans }} \\
& \varepsilon_{b}=\alpha_{8} \cdot\left(\frac{1}{D}\right)^{\alpha_{6}} \cdot\left(\frac{1}{v_{s g}-U_{\text {trans }}}\right)^{\alpha_{7}} \cdot\left(v_{\text {sg }}-U_{\text {trans }}\right)^{0.8} \cdot \exp \left(-\alpha_{10} \cdot \varepsilon_{s}\right) \\
& \varepsilon_{s}>0.1
\end{aligned}
$$

Determination of the transition parameters $\left(\varepsilon_{\text {trans }}\right.$ and $\left.\mathrm{V}_{\text {small }}\right)$ :

$$
\begin{gathered}
\frac{\varepsilon_{\text {trans }}}{\varepsilon_{\text {trans }}^{\text {ref }}}=\left(\frac{\rho_{g}}{\rho_{g}^{r e f}}\right)^{\alpha_{1}} \cdot \exp \left(\left(\alpha_{2} \cdot \ln \left(\frac{\rho_{g}}{\rho_{g}^{r e f}}\right)-\alpha_{3}\right) \cdot \varepsilon_{s}\right) \\
\left(\frac{V_{\text {small }}}{V_{\text {small }}^{\text {ref }}}\right)=\left(1+\frac{\alpha_{4}}{V_{\text {small }}^{\text {ref }}} \cdot \varepsilon_{s}\right)
\end{gathered}
$$

\subsection{Gas/Liquid Mass Transfer}

There are a lot of correlations in the literature, which gave different values of $k_{L} \cdot a$. According to this wide range of prediction, it was decided to take the same value of $k_{L} \cdot a$ for $\mathrm{CO}$ and $\mathrm{H}_{2}$. For the moment this value is fixed at $0.6 \mathrm{~s}^{-1}$ (average value determined from the numerous literature correlations) (Charpentier, 1981; Albal et al., 1984).

\subsection{Resolution of the Equations}

A discretization of Equations $(10,11,13,15,17)$ is performed in order to define a system of non-linear equations. An explicit numerical scheme is used and convergence is achieved when accumulation terms are equal to zero. Atomic balances are controlled between the reactor inlet and outlet.

\subsection{Boundary Conditions}

The boundary conditions for the reactant transport equations in the liquid phase are (Danckwerts, 1951):

$$
-\left.D_{a x} \cdot \frac{\partial C_{\mathrm{CO}}}{\partial z}\right|_{z=0}=0, \quad-\left.D_{a x} \cdot \frac{\partial C_{\mathrm{CO}}}{\partial z}\right|_{z=H}=0
$$

dispersion closed at the reactor inlet and outlet

$$
-\left.D_{a x} \cdot \frac{\partial C_{\mathrm{H}_{2}}}{\partial z}\right|_{z=0}=0, \quad-\left.D_{a x} \cdot \frac{\partial C_{\mathrm{H}_{2}}}{\partial z}\right|_{z=H}=0
$$

The boundary conditions for the heat transport equation in the liquid phase are:

$$
-\left.\lambda_{a x} \cdot \frac{\partial T}{\partial z}\right|_{z=0}=0, \quad-\left.\lambda_{a x} \cdot \frac{\partial T}{\partial z}\right|_{z=H}=0
$$

dispersion closed at the reactor inlet and outlet

\subsection{Reactor Temperature Regulation}

In order to find the cooling temperature which is necessary to reach reactor temperature setpoint, a PID controller were implemented in the model.

\subsection{General Reactor Scheme and Corresponding Algorithm}

Figure 6 shows the general reactor scheme which was modeled. Fresh syngas can be mixed with gas coming from reactor outlet after condensation. The reactor temperature is controlled by the vaporization of boiling feed water. The pressure of the steam drum is adjusted thanks to a PID controller link to the reactor setpoint. Figure 7 shows the corresponding algorithm of the model.

\section{MODEL VALIDATION}

Table 4 gives a set of operating conditions of the demonstration unit working in Sanazarro.

Table 5 shows the comparison of the reactor performances between the model and the experimental data. Table 6 shows the comparison of the outlet gas analysis between the model and the experimental data. A good agreement is obtained between the experimental data and the model. 


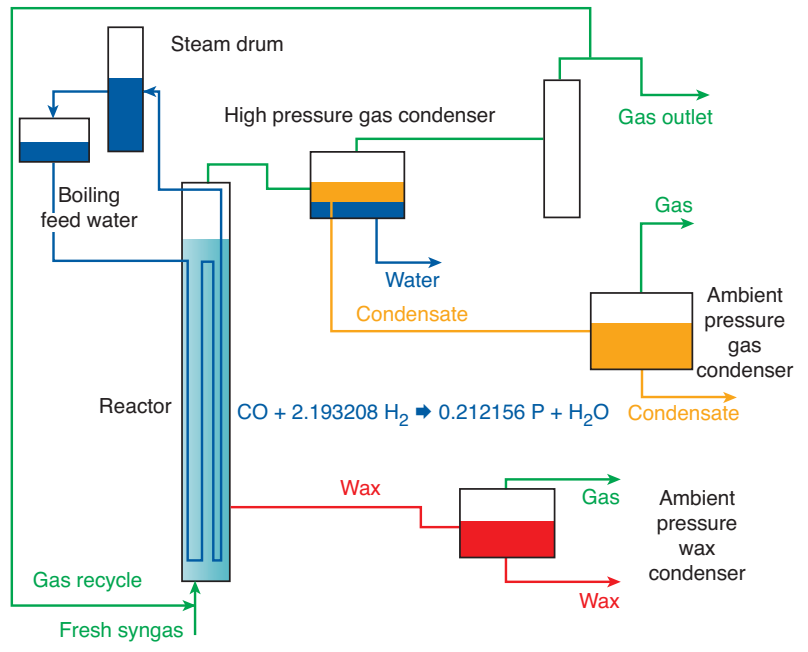

Figure 6

General reactor scheme.

TABLE 4

Operating conditions

\begin{tabular}{c|c}
\hline Reactor geometry & \\
\hline Reactor diameter & $0.5 \mathrm{~m}$ \\
\hline Reactor height & $10 \mathrm{~m}$ \\
\hline Operating conditions & \\
\hline Pressure $($ bar $)$ & 21.5 \\
\hline Temperature $\left({ }^{\circ} \mathrm{C}\right)$ & 215 \\
\hline Syngas flow-rate $\left(\mathrm{Nm}^{3} / \mathrm{h}\right)$ & 625 \\
\hline Syngas dilution $(\% \mathrm{vol})$ & 23.5 \\
\hline Slurry characteristics & \\
\hline Volumetric solid concentration $(\% \mathrm{vol})$ & 17 \\
\hline
\end{tabular}

TABLE 5

Comparison of the reactor performances model/experience

\begin{tabular}{c|c|c}
\hline & SNZ & Model \\
\hline Conversion $(\%)$ & 48 & 48.95 \\
\hline $\mathrm{H}_{2} / \mathrm{CO}$ out & 2.07 & 2.07 \\
\hline Gas holdup $(\% \mathrm{vol})$ & 24 & 21.06 \\
\hline Condensate $(\mathrm{kg} / \mathrm{h})$ & 18.86 & 18.74 \\
\hline Wax $(\mathrm{kg} / \mathrm{h})$ & 10.25 & 9.67 \\
\hline Water $(\mathrm{kg} / \mathrm{h})$ & 57.38 & 58.17 \\
\hline$T$ at $0.8 \mathrm{~m}\left({ }^{\circ} \mathrm{C}\right)$ & 214.82 & 214.82 \\
\hline$T$ at $3 \mathrm{~m}\left({ }^{\circ} \mathrm{C}\right)$ & 215.01 & 214.96 \\
\hline$T$ at $7 \mathrm{~m}\left({ }^{\circ} \mathrm{C}\right)$ & 214.93 & 215.05 \\
\hline$T$ at $13.5 \mathrm{~m}\left({ }^{\circ} \mathrm{C}\right)$ & 215.65 & 215.02 \\
\hline$T$ cooling $\left({ }^{\circ} \mathrm{C}\right)$ & not given & 211.37 \\
\hline
\end{tabular}

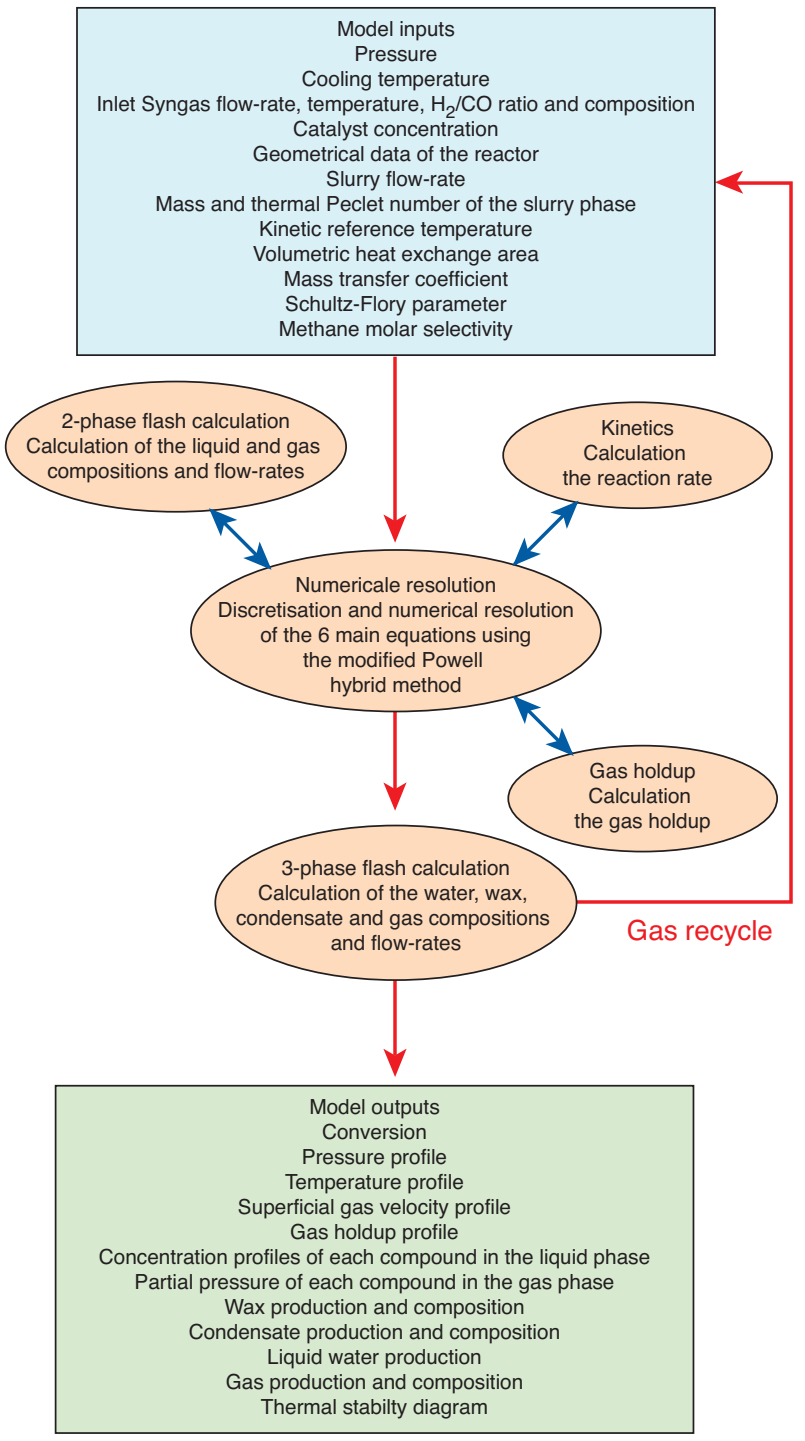

Figure 7

Model algorithm.

\section{Wax and Condensate Analysis}

Schulz-Flory parameters for paraffins and olefins were obtained from experiments performed in lab scale. These values lead to a good prediction of wax and condensate production. It is also interesting to compare condensate and wax analysis with the ones predicted by the model. Figure 8 shows the condensate composition obtained from the analysis and compared with the model prediction. A good agreement between the analysis and the model is obtained for paraffins and olefins.

Concerning the wax analysis, the agreement between the model and the experiments is not so good (see Fig. 9). 


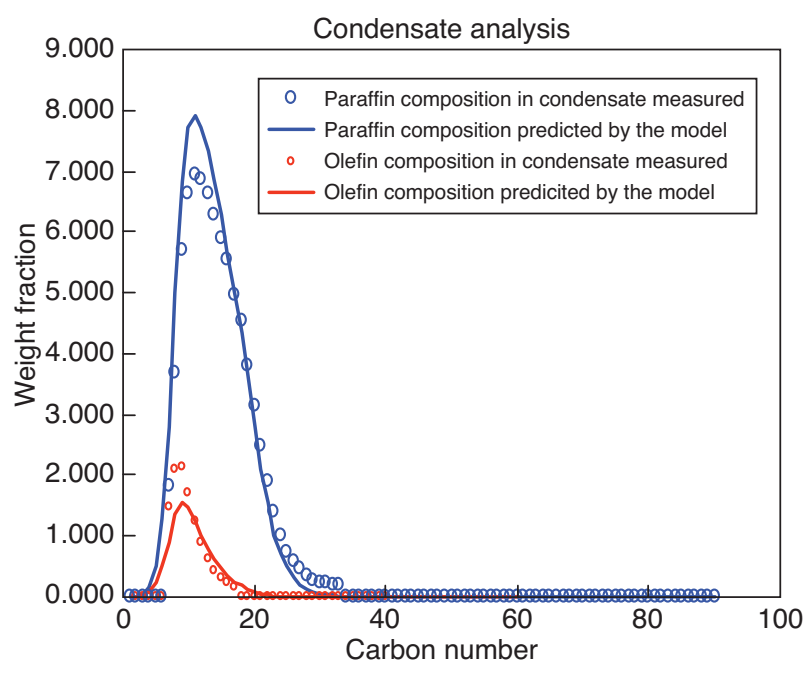

Figure 8

Condensate analysis.

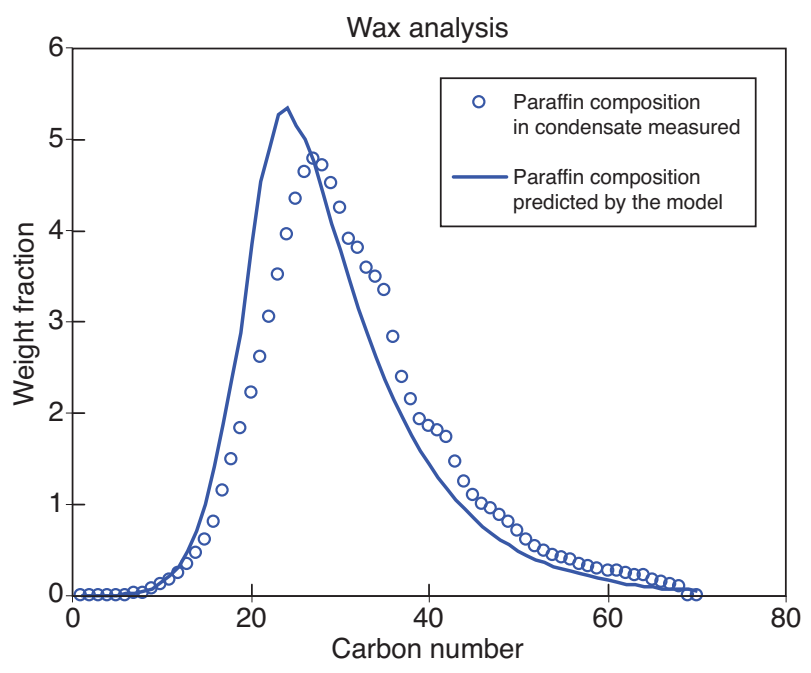

Figure 9

Wax analysis.
However, the wax analysis is not representative to the real composition of the wax produced. In fact, at the beginning of the run, the reactor was filled with a paraffinic mixture, which has a different composition than the one of the wax produced. It takes a long time to remove the startup mixture and to reach a representative composition of the wax produced. Due to the low wax production and the high liquid holdup, the wax analysis is still modified because of the presence startup mixture.

TABLE 6

Comparison of the outlet gas analysis model/experience

\begin{tabular}{c|c|c}
\hline Gas composition \%vol & SNZ & Model \\
\hline $\mathrm{CO}$ & 19.9 & 19.47 \\
\hline $\mathrm{H}_{2}$ & 41.22 & 40.3 \\
\hline $\mathrm{H}_{2} \mathrm{O}$ & 0.09 & 0.56 \\
\hline $\mathrm{Inert}$ & 36.12 & 36.42 \\
\hline $\mathrm{C} 1$ & 1.99 & 1.93 \\
\hline $\mathrm{C} 2$ & 0.129 & 0.176 \\
\hline $\mathrm{C} 3$ & 0.28 & 0.154 \\
\hline $\mathrm{C} 4$ & 0.206 & 0.134 \\
\hline $\mathrm{C} 5$ & 0.169 & 0.12 \\
\hline $\mathrm{C} 6$ & 0.08 & 0.09 \\
\hline $\mathrm{C} 7$ & 0.05 & 0.06 \\
\hline $\mathrm{C} 8$ & 0.01 & 0.03 \\
\hline $\mathrm{C} 9$ & 0.003 & 0.01 \\
\hline
\end{tabular}

\section{CONCLUSIONS}

The reactor model is a useful tool to predict the reactor performances. The validation of this model highlights that we will be able with this tool to give a design of an industrial unit with a reasonable degree of confidence. Now, it is used for the reactor scale-up and gives support on the future design of an industrial unit. At the present time, the most important uncertainties are linked to the catalyst parameters, which are relative to the chosen catalyst and its range of operating conditions (Kinetic reference temperature and Schulz-Flory parameter). To determine these parameters, we need validated results from catalytic tests in small reactors (Autoclave) giving the activity and the selectivity of the new catalyst.

\section{REFERENCES}

Albal R.S., Shah Y.T., Carr N.L., Bell A.T. (1984) Mass transfer coefficients and solubilities for hydrogen and carbon monoxide under Fischer-Tropsch conditions, Chem. Eng. Sci. 39, 5, 905-907.

Bach H.F., Pilhofer T. (1978) Variation of gas hold-up in bubble columns with physical properties of liquids and operating parameters of columns, Ger. Chem. Eng. 1, 270-275.

Baird M.H., Rice R.G. (1975) Axial dispersion in large unbaffled columns, Chem. Eng. J. 9, 171-174.

Berg S. (1993) Zur gasgehaltsverteilung und zum verweilzeitverhalten der gasphase in blasensäulen mit längsangeströmten rohrbündeleinbauten (Gas holdup and the residence time of the gas phase in bubble columns with internals), Dissertation, Universität Dortmund. Calderbank P.M., Moo-Young M.B. (1961) Chem. Eng. Sci. 16, 39. Charpentier J.C. (1981) Mass-transfer rates in gas-liquid absorbers and reactors, $A d v$. Chem. Eng. 11, 1-133. 
Clark K.N. (1990) The effect of high pressure and temperature on phase distributions in a bubble column, Chem. Eng. Sci. 45, 8 , 2301-2307.

Danckwerts P.V. (1951) Ind. Eng. Chem. 43, 1460.

Deckwer W.-D. (1992) Bubble Column Reactors, Wiley \& Sons Ltd. Eds., Chichester, England.

De Swart J.W.A., van Vliet R.E., Krishna R. (1996) Size, structure and dynamics of "large" bubbles in a two-dimensional slurry bubble column, Chem. Eng. Sci. 51, 4619-4629.

Fan L.S. (1989) Gas-liquid-solid fluidization engineering, Stoneham MA: Butterworth.

Fischer F., Tropsch H. (1921) Synthesis of methanol from CO and $\mathrm{H}_{2}$ French patent 540, 543 .

Froment G.F., Bischoff K. (1979) Chemical Reactor Analysis And Design, John Wiley \& Sons.

Gandhi B., Prakash A., Bergougnou M.A. (1999) Hydrodynamics behavior of slurry bubble column at high solids concentrations, Powder Technol. 103, 80-94.

Hills J.H. (1974) Radial non-uniformity of velocity and voidage in a bubble column, Trans. Inst. Chem. Eng. 52, 1-9.

Idogawa K., Ikeda K., Fukuda T., Morooka S. (1987) Int. Chem. Eng. 37, 93.

Jiang P., Lin T.-J., Luo X., Fan L.-S. (1995) Flow visualisation of high pressure $(21 \mathrm{MPa})$ bubble column: bubble characteristics, Trans. IChemE 73, A, 269-274.

Joshi J.B., Parasu Veera U., Prasad Ch.V., Phanikumar D.V., Deshphande N.S., Thakre S.S., Thorat B.N. (1998) Gas hold-up structure in bubble column reactors, PINSA Review article 64, A, 4, 441-567.

Keitel G., Onken U. (1982) Inhibition of bubble coalescence b solutes in air/water dispersions, Chem. Eng. Sci. 37, 11, 1635-1638.

Kelkar B.G., Shah Y. (1984) Hydrodynamics and axial mixing in a three-phase bubble column, Ind. Eng. Chem. Process Des. Dev. 23, 308-313.

Kemoun A., Chen Ong B., Gupta P., Al-Dahhan M.H., Dudukovic M.P. (2001) Gas holdup in bubble columns at elevated pressure via computed tomography, Int. J. Multiphas. Flow 27, 929-946.

Kluytmans J.H.J., van Wachem B.G.M., Kuster B.F., Schouten J.C. (2001) Gas holdup in a slurry bubble column: influence of electrolyte and carbon particles, Ind. Eng. Chem. Res. 40, 5326-5333.

Krishna R., Wilkinson P.M., Van Dierendonck L.L. (1991) A model for gas holdup in bubble columns incorporating the influence of gas density on flow regime transitions, Chem. Eng. Sci. 46, 10, 2491-2496.
Krishna R., Ellenberger J. (1996) Gas holdup in bubble column reactors operating in the churn-turbulent regime, AIChE J. 42, 2627-2634.

Krishna R., Urseanu M.I., Van Baten J.M., Ellenberger J. (1999) Rise velocity of a swarm of large bubbles in liquids, Chem. Eng. Sci. 54, 171-183.

Krishna R., Urseanu M.I., de Swart J.W.A., Ellenberger J. (2000) Gas holdup in bubble columns : operation with concentrated slurries versus high viscosity liquid, Can. J. Chem. Eng. 78, 442-447.

Krishna R. (2000) A scale-up strategy for a commercial scale bubble column slurry reactor for Fischer-Tropsch synthesis, Oil Gas Sci.Technol. - Rev. IFP 55, 4, 359-393.

Mills P.L., Turner J.R., Ramachadran P.A., Dudukovic M.P. (1996) The Fischer-Tropsch synthesis in slurry bubble column reactors: analysis of reactor performance using the axial dispersion model, Three-Phase Sparged Reactors, Topics in Chem. Eng. 8, 339-386.

Miyauchi T., Shyu C.N. (1970) Flow of fluid in gas bubble columns, Kagaku Kogaku 34, 958-964.

Nigam D.P., Schumpe A. (1996) Three-phase sparged reactors, Topics in Chem. Eng. 8.

Reilly I.G., Scott D.S., De Bruijn T.J.W., Jain A., Piskorz J. (1986) A correlation for gas holdup in turbulent coalescing bubble columns, Can. J. Chem. Eng. 64, 705-717.

Reith T., Renken S., Israel B.A. (1968) Gas holdup and axial mixing in the fluid phase of a bubble column, Chem. Eng. Sci. 23, 619-629.

Sarup B., Wojciechowski B.W. (1989) Studies of the FischerTropsch synthesis on a Cobalt catalyst II. Kinetics of carbon monoxide conversion to methane and to higher hydrocarbons, Can. J. Chem. Eng. 67, 62-74.

Schulz H., Beck K., Erich E. (1988) Kinetics of Fischer-Tropsch selectivity, Fuel Process Technol. 18, 293-304.

Shah Y.T., Kelkar B.G., Godbole S.P., Deckwer W.-D. (1982) Design parameters estimations for bubble column reactors, AIChE J. 28, 353-379.

Urseanu M.I. (2000) Scaling up bubble column reactors, $P h D$ Thesis, University of Amsterdam, Amsterdam.

Wilkinson P.M., van Dierendonck L.L. (1990) Pressure and gas density effects on bubble break-up and gas holdup in bubble columns, Chem. Eng. Sci. 45, 8, 2309-2315.

Final manuscript received in December 2008 Published online in March 2009

Copyright (C) 2009 Institut français du pétrole

Permission to make digital or hard copies of part or all of this work for personal or classroom use is granted without fee provided that copies are not made or distributed for profit or commercial advantage and that copies bear this notice and the full citation on the first page. Copyrights for components of this work owned by others than IFP must be honored. Abstracting with credit is permitted. To copy otherwise, to republish, to post on servers, or to redistribute to lists, requires prior specific permission and/or a fee: Request permission from Documentation, Institut français du pétrole, fax. +33 147527078 , or revueogst@ifp.fr. 